It will certainly be a standard work of reference for many years to come.

The work has this clearly defined purpose; and it is not within its seope to give descriptions or illustrations of species, and still less their life-histories. It does, however, mention the distinctive characters of sub-species, in order to indicate the trends of variation. Some information is also given about habitat, which is relevant to distribution, although, as the author points out, its nature varies geographically and seasonally, and can in the longer term be influenced by changing environmental factors.

Thus, Dr. Vaurie has kept to his particular and surely sufficient task of systematic presentation, based on many years of work in the principal museums of Europe and North America; the institution which he scrves, the American Museum of Natural History in New York, nowadays has the Rothschild Colloction earlier used by Hartert at Tring. The author has worked in close touch with Soviet ornithologists, and this has been of great help in enabling him to deal effectively with the forms found in northern Asia. In the course of his investigations he has published many notes on particular groups, allowing him now to give the end-results without detailed discussion except where it is desired to direct attention to some outstanding problem. All references to other sources have been checked by him with the original publications. The whole massive undertaking bears the stamp of expert authority.

In his taxonomic presentation, Dr. Vaurie directs particular attention to the trends of intraspecific geographical variation. There is a welcome flexibility in dealing with sub-species, which he places in three grades of validity-well differentiated, not well differentiated but acceptable, and unaccepted but worthy of mention (mostly points on a cline).

The other facet of the presentation gives the distribution of each species and sub-species within the region. The information is given in some detail and is a most valuable feature of the book. Extra-limital distribution and the existence of extra-limital sub-species are more briefly indicated.

Although other taxonomists may not accept the author's judgment on every point, the existence of this work will constitute a challenge to state reasons for any different practice. Ornithologists in general may be less willing to follow Dr. Vaurie in certain unexplained departures from the traditional order of species within a genus, or of genera within a family; these sequences have long since ceased to be regarded as more than convenient, and it is not clear that new arrangements have any special merit.

LANDSBOROUGH THOMSON

\section{TOWARDS A STRATEGY OF MATURITY}

\section{The Scientific Age}

The Impact of Science on Society. By L. V. Berkner. Pp. xvi+137. (New Haven and London: Yale University Press, 1964.) 30s.

T these Turnbull Lectures, delivered at the University of Yale, Mr. L. V. Berkner discusses in succession the economy of plenty, advanced education for a new age, the relations between science and government, science and philosophy, and what he terms "a strategy of maturity". In the first he explains the significance of science and technology for the economy of the United States as a whole. However, while he emphasizes the way in which science and technology contribute to the stability of the economy, his attitude is startlingly different from that of Prof. J. K. Galbraith. He seems inclined to advocate production and change for their own sake: he never challenges the tendency for the process of production to create 'needs'. His more constructive and fundamental thinking is found in later chapters, for example, when he considers the place of the universities in the changing society of the United States. Despite the close relations to conditions prevailing in the United States, of which he is somewhat critical, his comments on high-school education and university education should be pondered in considering the expansion of higher education in Britain, particularly in relation to the proportion of technicians to postgraduates who are being trained.

In his chapter on the role of the universities he comments freely on Clark Kerr's The Uses of the University, and again refers to this in his brief outline of the problems of Government finance for research and the selection of research projects. Here also he is critical of present-day policies and urges that up to 35 per cent of overhead expenses should be allowed against direct costs under research grants as encouraging institutional support for younger and unknown scientists, and the initiation of new, but soundly conceived, projects as well as encouraging better internal administration of public funds and greater freedom for the scientist while reducing Federal control of the institution. Much of his discussion of science and philosophy stems from Lord Snow's The Two Cultures, the broad thesis of which he accepts. This he regards as fundamentally a problem of communication. He is concerned that failure to comprehend the character and power of the means available for improving the condition of the bulk of mankind may lead to the degeneration of our civilization. This is a task which calls for the contribution of the humanist as well as of the scientist if we are to achieve the discipline of mind and body that will master the machine.

When he outlines his "strategy of maturity", Mr. Berkner comes nearer to the point of view of Prof. Galbraith. $\mathrm{He}$ considers that at present the educational capacity of the United States, particularly with regard to the proportions of learning and skill required, the policies governing the encouragement of science and the attitudes of society generally, are potential sources of instability. Causing instability also in a similar fashion are: the potential elimination of poverty by extending to every level of society the opportunity for higher education; the increasing lack of balance in social opportunity in a world divided between the highly industrialized nations and the underdeveloped areas; and the radical change in the character of war and of justice among nations.

On the educational side, he looks for a solution to the improvements in curricula and in teaching at the elemen. tary and secondary school level which are already leading to progress in individual capacity, as well as to improved articulation between school and university. Improvements which could also help include increasing the opportunities for students to participate in research at an early age with more effective presentation of the idea content in university courses, and the shift of professional emphasis and specialization to the graduate school. However, he suggests that in the next decade in the United States the emergence of the junior college may be the most farreaching development, and this suggestion also has its implications for Britain. He has some cogent observations on the character of business management and on training for management and more especially on relations between business and industry. He writes with brevity and realism on social change, the problem of poverty and population and the challenge of the underdeveloped peoples. Implicit in it all is the insistence on honest and clear thinking regardless of political prejudice. We must face frankly the real issues of the time, and a strategy of maturity would arise from any rational attitude of mind that evaluates alternatives objectively and tests each step analytically, seeking to utilize the optimum advantages that our scientific culture affords. Outside the American context, Mr. Berkner offers little in the way of constructive proposals, but nevertheless he is as challenging and stimulating for the British readers as for the American audience he originally addressed.
R. BRIGHTMAN 